\title{
CDISC SEND Study Report Status Response Terminology
}

National Cancer Institute

\section{Source}

National Cancer Institute. CDISC SEND Study Report Status Response Terminology. NCI

Thesaurus. Code C158125.

Terminology associated with the study report status response codelist of the Clinical Data Interchange Standards Consortium (CDISC) Standard for the Exchange of Nonclinical Data (SEND). 